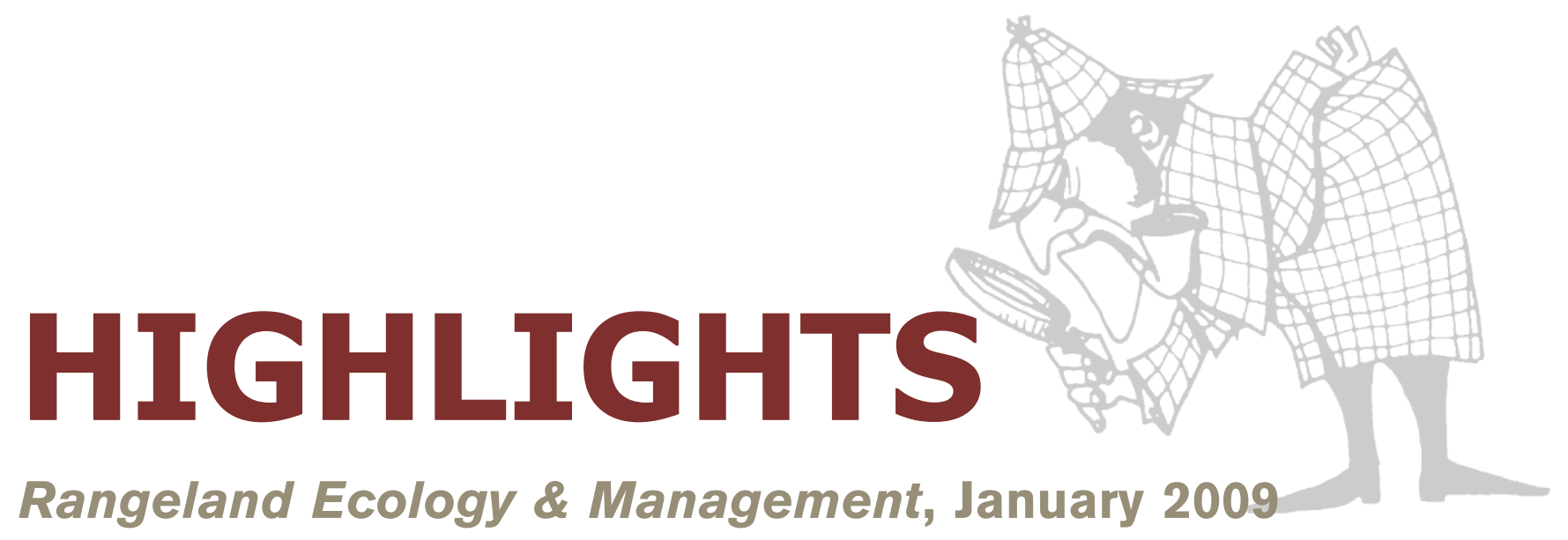

State-and-Transition Models for

Heterogeneous Landscapes: A Strategy for Development and Application

Brandon T. Bestelmeyer, Arlene J. Tugel, George L. Peacock, Jr., Daniel G. Robinett, Pat L. Shaver, Joel R. Brown, Jeffrey E. Herrick, Homer Sanchez, and Kris M. Havstad

Although general concepts surrounding state-and-transition models (STMs) and ecological sites have received increasing attention, strategies to apply and quantify these concepts have not. We offer a state-of-the-art summary of the linkages between ecological sites and STMs and then outline steps of a practical approach to the coupled development of STMs and ecological sites at landscape to regional scales. Quantification emphasizes inventory techniques readily available to natural resource professionals and the linkage of inventory to expert knowledge and site-based mechanistic experiments and monitoring. We provide a simple example of how inventory can be used to refine ecological sites and STMs.

\section{Leafy Spurge (Euphorbia esula) Classification Performance Using Hyperspectral and Multispectral Sensors}

Jessica J. Mitchell and Nancy F. Glenn

Remote sensing can potentially be used as a tool for management of leafy spurge (Euphorbia esula L.). It is generally accepted that hyperspectral data can adequately identify leafy spurge. However, the detection limits of leafy spurge within more commonly available multispectral data are not well understood. We investigated the spatial and spectral detection limits of Landsat with hyperspectral and field data in a heavily infested demonstration area. Results indicate that the Landsat sensor is inadequate for regional monitoring and that high spectral resolution may not be critical to leafy spurge discrimination. A next-generation Landsat sensor with comparable resolution but improved instrumentation (e.g., signal-to-noise ratio) may offer an alternative to hyperspectral data for mapping leafy spurge at regional scales.

\section{Practical Challenges in Private Stewardship of Rangeland Ecosystems: Yellow Starthistle Control in Sierra Nevadan Foothills}

Clare E. Aslan, Matthew B. Hufford, Rebecca S. Epanchin-Niell, Jeffrey D. Port, Jason P. Sexton, and Timothy M. Waring

Despite extensive weed-control research, yellow starthistle (Centaurea solstitialis) continues to spread across Californian rangelands, endangering the livelihoods of longtime ranchers. To identify causes of control failure, we surveyed and interviewed 202 cattle ranchers in four counties. Most participant ranchers had attempted to control yellow starthistle, but their efforts were hindered by insufficient planning for long-term control, misinformation about control techniques and weed biology, and the difficulty of tailoring control methods to variable landscapes. Unless these gaps between control science and practice can be bridged, yellow starthistle will continue to reduce ranch productivity and promote rangeland conversion for development.

\section{Cattle Grazing as a Biological Control for Broom Snakeweed: Vegetation Response}

\section{Michael H. Ralphs and Jeffery E. Banks}

Although overgrazing is a principal cause of broom snakeweed (Gutierrezia sarothrae) dominance, targeted grazing may be an effective biological tool to control it. A 4-year grazing study was conducted in spring and late summer in which cattle were restricted to narrow grazing lanes to control herbaceous forage allowance. Density of mature snakeweed plants declined to a greater degree in grazed areas than in ungrazed areas. Intensive grazing did not 
reduce crested wheatgrass cover under spring grazing, and it actually increased in the summer grazing trials. Snakeweed was controlled without adversely affecting associated species in a crested wheatgrass plant community.

\section{Cool-Season Floodplain Meadow Responses to Shrub Encroachment in Alberta}

\section{Edward W. Bork and Angela M. Burkinshaw}

Widespread shrub encroachment of cool-season riparian floodplains in southwest Alberta is thought to reduce biodiversity and productivity, potentially escalating land use conflict. We assessed overstory and understory characteristics of plant communities known to be affected by variable degrees of shrub encroachment. While understory diversity peaked at moderate (64\%) shrub cover, even small increases in shrub-canopy closure (up to 35\%) were associated with sharp declines $(-58 \%)$ in herbage production. The retention of key livestock and wildlife grazing opportunities in floodplain meadows of the region appears contingent on maintaining a low level of shrub cover, which in turn may require active restoration.

\section{Do Introduced Grasses Improve Forage Production on the Northern Mixed Prairie? \\ Walter D. Willms, Toby Entz, Ryan Beck, and Xiying Hao}

The relative benefit of introducing forages to native prairies has been controversial. We compared the productivity of crested wheatgrass (CWG; Agropyron cristatum) and Russian wildrye (RWR; Psathyrostachys junceus) with native species at two sites (Stipa-Agropyron-Bouteloua [SAB], StipaBouteloua [SB]) over 12 years in the northern mixed prairie. CWG was more productive than the native grasses on the more xeric SB site, but it had similar productivity on the $\mathrm{SAB}$ site, while RWR was less productive than CWG on both sites. The study confirms the relative yield advantage of CWG to the native grasses on the SB site, but loss of species diversity severely reduces its ecological benefits.

\section{Mycorrhizal Hyphal Length as a Function of Plant Community Richness and Composition in Restored Northern Tallgrass Prairies (USA)}

\section{Marcus A. Bingham and Mario Biondini}

This research indicates that, in order to promote mycorrhizal hyphal length in restored northern tallgrass prairies, at least three factors need to be given priority: 1) achieving high levels of species and functional form richness; 2) making sure that late successional $\mathrm{C} 4$ (warm-season) grasses are present; and 3) ensuring that seed mixtures include species that are characterized by high root-to-shoot ratios, high root density, and high nitrogen-use efficiency.
Multispecies Allometric Models Predict Grass Biomass in Semidesert Rangeland

Aleta M. Nafus, Mitchel P. McClaran, Steven R. Archer, and Heather L. Throop

Can a single equation accurately predict grass biomass from basal diameter for eight different species? We addressed this question by comparing separate regression equations for each species with an equation for all eight species combined. We found that a single equation for all eight species was very accurate (adj. $\left.R^{2}=0.85\right)$ compared to separate equations (adj. $\left.R^{2}=0.80-0.91\right)$. The biomass-diameter relationship is nonlinear (mass $=\mathrm{e}^{1.441} \mathrm{x}$ diameter ${ }^{1.25}$ ), so mass doubles with only a $75 \%$ increase in diameter. A single predictive equation should improve time efficiency in the field because species identification will not be necessary.

\section{Fragmentation Status of Tall-Tussock Grassland Relicts in the Flooding Pampa, Argentina}

Lorena P. Herrera, Pedro Laterra, Néstor O. Maceira, Karina D. Zelaya, and Gustavo A. Martínez

Since European settlement in the pampas of Argentina, vast areas of native tall tussock grassland dominated by Paspalum quadrifarium ("pajonal") were converted to croplands and short-grass prairies. Using remote sensing data, we studied current pajonal cover and fragmentation over 2,173,600 ha dominated by this ecosystem 50 years ago. Current cover by pajonal was $32.5 \%$, and fragmentation was more severe in soils with less restriction for agriculture. The principal replacement ecosystems were short grasslands and annual crop fields. These results represent an important input for developing policies of biodiversity conservation, landscape planning, and sustainable management of these grasslands.

\section{Plant Interspaces Resulting From Contrasting Grazing Management in Northern Mixed-Grass Prairie: Implications for Ecosystem Function}

\section{Justin D. Derner and Ashley J. Whitman}

Livestock grazing can potentially modify plant interspaces by altering the horizontal structure of vegetation at the soil surface through grazing-induced effects on the relative composition of bunchgrasses and rhizomatous grasses. We assessed how contrasting long-term (25 years) grazing management (heavily grazed vs. ungrazed) influenced plant interspaces in northern mixed-grass prairie. Numbers of plant interspaces were $26 \%$ higher, sizes of plant interspaces were smaller, and litter cover in plant interspaces was lower in heavily grazed pastures. Management practices which increase the cover of litter in plant interspaces should reduce the potential of erosion from water and wind in this semiarid rangeland. 


\section{Vegetation Responses to Prescribed Burning of Grazed Shortgrass Steppe}

\section{David J. Augustine and Daniel G. Milchunas}

Prescribed fire may be a useful tool for certain management objectives in shortgrass rangeland, but the effect on forage production is a concern for managers. We studied the effects of prescribed burns on plant production, forage nitrogen content, and plant species composition of shortgrass steppe in northeastern Colorado. Late-winter burns on moderately grazed sites did not negatively affect forage production in most years, temporarily suppressed broom snakeweed and prickly pear cactus, and enhanced forage nitrogen content during the first post-burn growing season. Our results suggest that, except following severe drought, late-winter burns in shortgrass steppe may have neutral or positive consequences for livestock.
Postfire Succession in Big Sagebrush

\section{Steppe With Livestock Grazing}

Jonathan D. Bates, Edward C. Rhodes, Kirk W.

Davies, and Robert Sharp

Determining the impacts of grazing is important for development of management strategies to successfully restore big sagebrush plant communities after fire. We evaluated herbaceous recovery after prescribed fire as influenced by timing of livestock grazing on Wyoming big sagebrush (Artemisia tridentata subsp. Wyomingensis [Beetle \& Young] Welsh) steppe in eastern Oregon. Recovery of herbaceous response variables (cover, density, composition, and annual yield), levels of bare ground, and litter did not differ among burn-grazed and burn treatments. The results demonstrated that grazing within 2 years following prescribed fire will not hinder the recovery of herbaceous plant communities in big sagebrush steppe. 


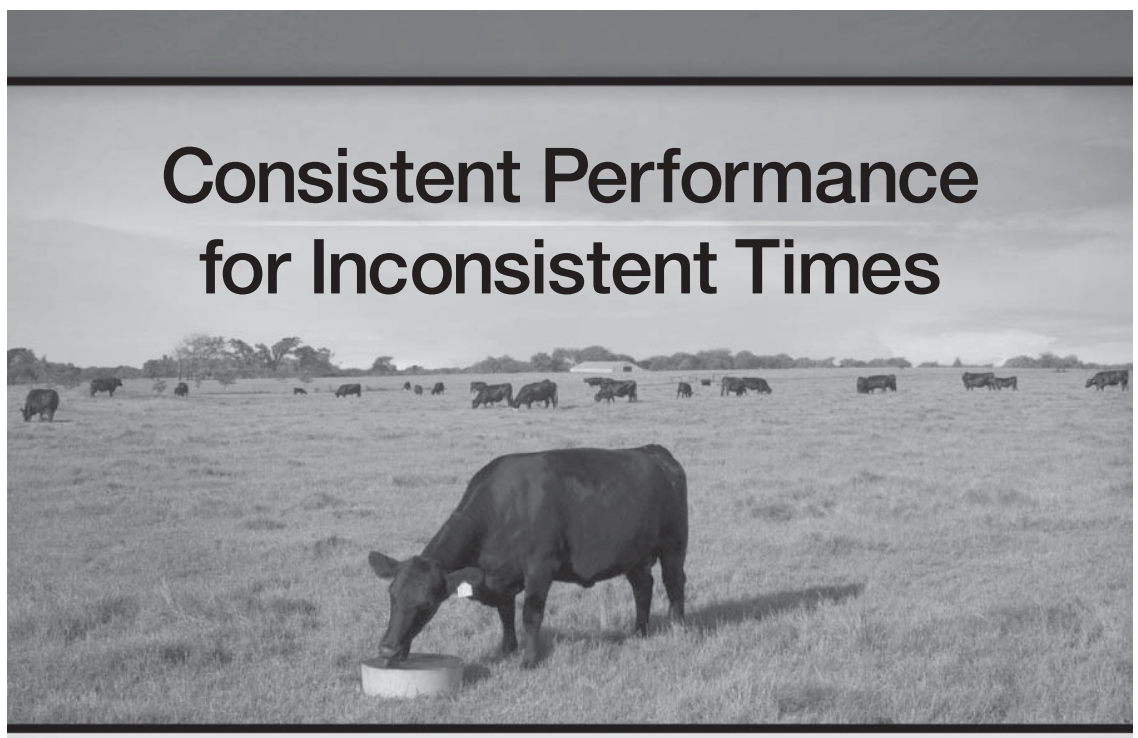

Markets go up. Markets go down. Yet year after year, CRYSTALYX ${ }^{\oplus}$ performance is one constant you can depend on to help increase returns. For over 30 years, we've been the preferred low-moisture block supplement program — backed by industry-leading production experience, nutrition expertise and research. CRYSTALYX ${ }^{\circledR}$ delivers consistent nutrition, consistent quality and consistent research-proven results ... all while consistently saving you time and money.

$$
\text { Cf }
$$

